\title{
Assessment of the Different Modalities of Treatment in Paediatric Cerebral Palsy Patients
}

\author{
Gaurang Dilip Kumar Pabani ${ }^{\oplus 1}$, Rajeshri Rajendra Mehta ${ }^{\circledR 2}$, Pramod Chandulal Shah ${ }^{\circledast 3}$ \\ ${ }^{1}$ Assistant Professor, Department of Pediatrics, GMERS Medical College and Civil Hospital, Sola, Ahmedabad, India, ${ }^{2}$ Assistant Professor, Department of Pediatrics, Dr. \\ M K Shah Medical College and Research Centre, Chandkheda, Ahmedabad, India, ${ }^{3}$ Associate Professor, Department of Pediatrics, Dr. M K Shah Medical College and \\ Research Centre, Chandkheda, Ahmedabad, India.
}

\section{Abstract}

Background: To assess the effects of injection of citicoline in combination with physiotherapy versus physiotherapy alone, to advance the functional outcome in paediatric patients with cerebral palsy. Subjects \& Methods: A total of 150 paediatric patients diagnosed with cerebral palsy were incorporated into the study. The average age of the patient included in the study was found to be 36 months. All the patients enrolled in the study were referred to the paediatric neurological department. Results: The mean age of the patient was $36 \pm 10$ months. Out of the 150 total patients, $60 \%$ were boys and $40 \%$ were girls. When the percentage of improvement was compared between the groups, the study group was established to be statistically significant. $(\mathrm{P}=0.02)$. Conclusion: Citicoline is efficient and secure in the treatment of gross motor function combination with physiotherapy in patients with cerebral palsy. Physical therapy is frequently the first move in managing cerebral palsy.

Keywords: Cerebral Palsy, Citicoline, Physiotherapy, Paediatric

Corresponding Author: Rajeshri Rajendra Mehta, Assistant Professor, Department of Pediatrics, Dr. M K Shah Medical College and Research Centre, Chandkheda, Ahmedabad, India.

E-mail: rajeshrimehta@yahoo.com

Received: 29 July 2020

Revised: 08 September 2020

Accepted: 15 September 2020

Published: 28 December 2020

\section{Introduction}

Diverse divisions of the brain manage the faction of each muscle of the body. In cerebral palsy, there is harm to or require of growth in, one of these regions of the brain. ${ }^{[1]}$ Cerebral palsy (CP) is the grouping of two words: 'Cerebral' - refers to the brain. 'Palsy' - can denote weakness or paralysis or be short of muscle control. So CP is a disarray of muscle control that results from several injuries to the division of the brain. CP is used when the difficulty has happened prematurely in life, to the developing brain. ${ }^{[2,3]}$ It is approximate that 2 out of each 1,000 newborn children will build up cerebral palsy. Presently, about 10,000 children and infants are detected with this form every year. CP is a recognizable difficulty, the universal frequency being 2 to 2.5 per 1000 live births. The description of the cerebral palsied child are paralysis, weakness, in harmonization, on some former deviation of motor function owing to the failure of the motor centers of the brain. ${ }^{[4,5]}$

There are numerous rationales why somebody may have cerebral palsy. ${ }^{[6]}$ An unborn child may undergo a brain injury, an infection, or irregular growth of the brain tissue. These reasons are accountable for $70 \%$ of the cases of cerebral palsy. Another $20 \%$ of cerebral palsy cases are due to brain damage that takes place through the birthing process. ${ }^{[7]}$

Efforts to differentiate persons with $\mathrm{CP}$ may happen for a variety of reasons: clinical explanation, forecast of future position, and to monitor changes in function. ${ }^{[8]}$ These processes insert information from some magnitude: Topography of the injury: the parts of the body that are caught up, Type of injury: is the body stiff, loose or shows irregular motor control, To a great extent of the strategic organization of cerebral palsy is meant at preventing increasing secondary injury and disability. Follow-up at usual intervals is vital in the best possible supervision of a child with cerebral palsy. ${ }^{[9]}$ The essential significance to the optimization of the functional outcome is the source of progress in new therapeutic wealth for use in arrangement with physical rehabilitation methods. Physiotherapy, use of orthotics, serial casting, electrical stimulation, and freshly, the intramuscular injection of botulinum toxin type are the largely widespread interventions. ${ }^{[10]}$ There is no drug that might be able to create the neurons to regenerate; stem cell therapy might be a hopeful technique in the future. Citicol- 
ine as a neuroprotectant has been gradually more standard that may perform together in early and late stages of ischemic damage, ensuing in a surfeit of investigational. ${ }^{[11]}$

Currently, in many countries, citicoline is approved for utilizing in stroke, head trauma, and other neurological disorders. Hence keeping the above points in mind the present research was intended to assess the effects of injection of citicoline in combination with physiotherapy versus physiotherapy alone, to advance the functional outcome in pediatric patients with cerebral palsy.

\section{Subjects and Methods}

The present study was carried out at the Department of Pediatrics, Dr. M K Shah Medical College and Research Centre, Chandkheda, Ahmedabad from January 2019 to August 2019. The present randomized controlled trial was conducted in accordance with the ethical committee of the institute. The ethical clearance certificate was obtained before the start of the study. A total of 150 paediatric patients diagnosed with cerebral palsy were included in the research. The average age of the patient included in the study was found to be 36 months. All the patients enrolled in the study were referred to the paediatric neurological department.

Paediatric patients with the etiology of prematurity and perinatal hypoxic-ischemic damage and absence of neurometabolic, neurodegenerative disorders, neuromuscular disorders and orthopaedic problems were included in the study. Patients with cerebral palsy due to other etiology factors were excluded from the study. All the parents were informed about the research and the written informed consent was signed by them. All the included patients were arbitrarily separated into two groups. Each group was comprised of 75 patients. History was recorded, age, gender, gestational age at delivery, type of cerebral palsy, type of delivery, electroencephalography change and gross motor function classification system (GMFCS) levels are the different variables were recorded in the study. In the first group which included 75 paediatric patients who were treated with physiotherapy only were designated as a control group. The study group comprised of 75 patients, all patients were treated with physiotherapy along with the injection of citicoline $(10 \mathrm{mg} / \mathrm{kg})$ for three months. GMFCS was assessed before and after the treatment. Collected data were subjected to statistical analysis with the help of SPSS software. T-test was used to compare the age between the groups. McNemar test was used to assess the GMFCS levels between the two groups.

\section{Results}

The mean age of the patient was found to be $36 \pm 10$ months. Out of the 150 total patients, $60 \%$ were boys and $40 \%$ were girls. The variable like age, gender, gestational age at delivery, type of cerebral palsy, type of delivery and EEG were reported in [Table 1].

[Table 2] illustrates the results of GMFCS distribution between the study groups. The comparison was done before and after treatment. Before treatment, GMFCS level 1 was not observed in all patients, whereas after treatment 39 patients showed GMFCS level 1. Twenty-seven patients out of a total of 33 patients with GMFCS level 2 in the case group did improve to GMFCS level 1 after treatment, nine of fifteen patients with GMFCS level 3 improved to higher function (six patients to GMFCS level 2 and three patients to GMFCS level 1). Nine of twenty-one patients with GMFCS level 4 improved to other levels (three improved to GMFCS level 2 and three improved to GMFCS level 3). In the control group, nine out of twentyseven patients with pre-treatment gross motor function level 2 improved to level 1 . Nine out of thirty patients with GMFCS level 3 improved to levels, and six out of twelve patients with GMFCS level 4 improved to higher levels. In total, GMFCS level in 64\% (42 patients) of cases was improved whereas in the control group $32 \%$ (24 patients) were improved. When the percentage of improvement was compared between the groups the difference in the study group was found to be statistically significant with $\mathrm{P}=0.02$.

The level of significance is considered to be $<0.05$.

The level of significance is considered to be $<0.05$.

\section{Discussion}

Cerebral palsy preteen's substantial diagnostic and therapeutic challenges to the physician with the degree of participation ranging from mild with a minimal disability to severe connected with several co-morbid conditions. It is the most common reason for neurological disability in childhood after autism and mental retardation and as numerous as $70 \%$ of children with cerebral palsy survive into adult life. ${ }^{[12,13]}$

Physical therapy is frequently the primary step in managing cerebral palsy. It can help get better motor skills and can avert association problems from getting poorer over time. Physical therapy equipment power and elasticity exercises, heat treatment, massages and special gear to give children with cerebral palsy more autonomy. ${ }^{[14,15]}$ The degree to which physical therapy assists depends on the severity and form of every case of cerebral palsy. Children with milder cases of CP may simply need some physical therapy to treat their situation. ${ }^{[16]}$ In more severe cases, it may be utilized next to other management or medications. Start physical therapy as early as possible typically provides children the greatest probability of progress. Citicoline is a narrative nutrient with a broad spectrum of profit for conditions connected with symptoms of neurological dysfunction. An endogenous compound, citicoline is a necessary intermediate in the 


\begin{tabular}{|c|c|c|c|}
\hline Features & $\begin{array}{l}\text { Control Group } \\
\text { (75) }\end{array}$ & Case Group (75) & P Value \\
\hline Age & $36 \pm 11$ months & $40 \pm 10$ months & 0.13 \\
\hline Gender Boy Girl & 4332 & 4728 & 0.17 \\
\hline Type of delivery Normal Cesarean & 2847 & 3342 & 0.23 \\
\hline $\begin{array}{l}\text { Type of cerebral palsy Spastic quadriplegia Spastic } \\
\text { diplegia }\end{array}$ & 3738 & 4035 & 0.19 \\
\hline Gestational age Term Preterm & 4332 & 3936 & 0.43 \\
\hline EEG Normal Abnormal & 1560 & 1065 & 0.32 \\
\hline
\end{tabular}

\begin{tabular}{lll}
\hline \multicolumn{2}{l}{ Table 2: Comparison of GMFCS Levels between the Study Group and the Control Group } & \\
\hline GMFCS & Before Treatment & After Treatment \\
\hline GMFCS 1 Study group Control group & 00 & 309 \\
\hline GMFCS 2 Study group Control group & 3327 & 1827 \\
\hline GMFCS 3 Study group Control group & 927 & 1530 \\
GMFCS 4 Study group Control group & 126 & 2112 \\
\hline GMFCS 5 Study group Control group & 66 & 66 \\
\hline P-Value & 0.06 & 0.34 \\
\hline
\end{tabular}

synthesis of cell membrane phospholipids and its formation is the rate-limiting step in phosphatidylcholine synthesis. ${ }^{[17]}$

Findings of the present research demonstrated that the combination of citicoline with physiotherapy significantly improved gross motor performance as compared to physiotherapy alone in cerebral palsy. The best effect was seen in a patient with GMFCS level 2 and 3. However, no change in the effect was found on the GMFCS level, 5 patients.

Citicoline has numerous significant mechanisms of the act leading to a broad variety of advantageous effects on neurological function. Citicoline principally operates by escalating the synthesis of phosphatidylcholine, the chief neuronal membrane phospholipid, and enhancing the manufacture of acetylcholine. ${ }^{[18]}$ Citicoline management appreciably increased the length and branch points of dendrites, rising on the whole surface area engaged by neurons, which directs to augmented effectiveness of sensory information processing. ${ }^{[19]}$

Very little research has been published in this aspect of the study. Hence the result of the present study can be considered as a baseline for the extensive work in this field. A relatively larger sample size should be planned and more extensive results can be obtained. More research on its dosage and combination with other drugs should be planned in the future.

\section{Conclusion}

Citicoline is useful and secure in the management of gross motor function grouping with physiotherapy in patients with cerebral palsy. Physical therapy is frequently the primary movement in treating cerebral palsy. It can assist advanced motor skills and can avert movement problems from getting poorer over time. However, before coming to any conclusion more extensive research should be planned and carried out. However, before coming to any conclusion more extensive research should be planned and carried out.

\section{References}

1. Geschwind N. The apraxias: Neural mechanisms of disorders of learned movement: The anatomical organization of the language areas and motor systems of the human brain clarifies apraxic disorders and throws new light on cerebral dominance. Am Sci. 1975;63(2):188-95.

2. Bax M, Goldstein M, Rosenbaum P, Leviton A, Paneth N, Dan B, et al.. Proposed definition and classification of cerebral palsy, April 2005; 2005. Available from: https://dx.doi.org/10. 1017/s001216220500112x.

3. Rosenbaum P, Paneth N, Leviton A, Goldstein M, Bax M, Damiano D. A Report: The Definition and Classification of Cerebral Palsy. Dev Med Child Neurol Suppl. 2006;109:8-14.

4. Ashwal S, Russman BS, Blasco PA, Miller G, Sandler A, Shevell M, et al. Practice Parameter: Diagnostic assessment of the child with cerebral palsy: Report of the Quality Standards Subcommittee of the American Academy of Neurology and the Practice Committee of the Child Neurology Society. Neurology. 2004;62(6):851-863. Available from: https://dx. doi.org/10.1212/01.wnl.0000117981.35364.1b. 
5. Jan MMS. Cerebral Palsy: Comprehensive Review and Update. Ann Saudi Med. 2006;26(2):123-132. Available from: https: //dx.doi.org/10.5144/0256-4947.2006.123.

6. Ingram TTS. The Neurology of Cerebral Palsy. Arch Dis Child. 1966;41(218):337-357. Available from: https://dx.doi.org/10. 1136/adc.41.218.337.

7. Stavsky M, Mor O, Mastrolia SA, Greenbaum S, Than NG, Erez O. Cerebral Palsy_-Trends in Epidemiology and Recent Development in Prenatal Mechanisms of Disease, Treatment, and Prevention. Front Pediatr. 2017;5:21. Available from: https://dx.doi.org/10.3389/fped.2017.00021.

8. Miller D, Grossman R, Reingold S, Mcfarland H. The role of magnetic resonance techniques in understanding and managing multiple sclerosis. Brain. 1998;121(1):3-24. Available from: https://doi.org/10.1093/brain/121.1.3.

9. Sharan D. Orthopedic surgery in cerebral palsy: Instructional course lecture. Indian J Orthop. 2017;51(3):240-255. Available from: https://dx.doi.org/10.4103/ortho.IJOrtho_197_16.

10. Nasiri J, Kargar M. Combination of citicoline and physiotherapy in children with cerebral palsy. Int J Prev Med. 2014;5(10):1308-1313.

11. Galea MP. Physical modalities in the treatment of neurological dysfunction. Clin Neurol Neurosurg. 2012;114(5):483-488. Available from: https://dx.doi.org/10.1016/j.clineuro.2012.01. 009.

12. Patel DS, Sharma N, Patel MC, Patel BN, Shrivastav PS, Sanyal M. Liquid Chromatography Tandem Mass Spectrometry Method For Determination Of Febuxostat In Human Plasma To Support A Bioequivalence Study. J Adv Pharm Technol. 2013;1(1):37-50. Available from: https://dx.doi.org/10.14302/ issn.2328-0182.japst-12-173.

13. Hirschberger RG, Kuban KCK, O'Shea TM, Joseph RM, Heeren T, Douglass L, et al. Co-occurrence and severity of neurodevelopmental burden (cognitive impairment, cerebral palsy, autism spectrum disorder, and epilepsy) at age 10 years in children born extremely preterm. Pediatr Neurol. 2018;79:4552. Available from: https://dx.doi.org/10.1016/j.pediatrneurol. 2017.11.002.
14. Das SP, Ganesh GS. Evidence-based Approach to Physical Therapy in Cerebral Palsy. Indian J Orthop. 2019;53(1):2034. Available from: https://dx.doi.org/10.4103/ortho.IJOrtho_ 241_17.

15. Shamsoddini A, Amirsalari S, Hollisaz MT, Rahimnia A, Khatibi-Aghda A. Management of Spasticity in Children with Cerebral Palsy. Iran J Pediatr. 2014;24(4):345-351.

16. Russman BS, Ashwal S. Evaluation of the child with cerebral palsy. Semin Pediatr Neurol . 2004;11(1):47-57. Available from: https://dx.doi.org/10.1016/j.spen.2004.01.007.

17. Weiss GB. Metabolism and actions of CDP-choline as an endogenous compound and administered exogenously as citicoline. Life Sci. 1995;56(9):637-60. Available from: https: //dx.doi.org/10.1016/0024-3205(94)00427-t.

18. Segura T, Calleja S, Jordan J. Recommendations and treatment strategies for the management of acute ischemic stroke. Expert Opin Pharmacother. 2008;9(7):1071-1085. Available from: https://dx.doi.org/10.1517/14656566.9.7.1071.

19. Pawar P, Ramakrishnan S, Mumbare S, Patil M. Effectiveness of the addition of citicoline to patching in the treatment of amblyopia around visual maturity: A randomized controlled trial. Indian J Ophthalmol. 2014;62(2):124-129. Available from: https://dx.doi.org/10.4103/0301-4738.128586.

Copyright: (C) the author(s), 2020. It is an open-access article distributed under the terms of the Creative Commons Attribution License (CC BY 4.0), which permits authors to retain ownership of the copyright for their content, and allow anyone to download, reuse, reprint, modify, distribute and/or copy the content as long as the original authors and source are cited.

How to cite this article: Pabani GDK, Mehta RR, Shah PC. Assessment of the Different Modalities of Treatment in Paediatric Cerebral Palsy Patients. Asian J. Clin. Pediatr. Neonatol. 2020; $8(4): 9-12$.

DOI: dx.doi.org/10.47009/ajcpn.2020.8.4.3

Source of Support: Nil, Conflict of Interest: None declared. 